\title{
Investigating the Difference between Constructional Perceptions and Real Perceptions of Man
}

\author{
Mohammad Taqi Rokni Lamouki
}

Staff Member of Imam Sadiq Research Institute for Islamic Sciences, Qom, Iran; Rokni44@yahoo.com

\section{Doi:10.5901/mjss.2016.v7n5s1p89}

\section{Abstract}

Relativism is one of the deviant thoughts of the modern era. This way of thinking can be discussed in two fields of epistemology and ethics. In epistemology, it means rejecting fixed, perfect and absolute existence and reality. Truth-seeking scholars have made efforts in order to counter this thought. Proving constructional concepts is among these efforts presented to the world of knowledge by Muslim scholars. By introducing constructional concepts and distinguishing them from real perceptions of man, they have sent this message to all of the people that reality is achievable for man. In the present article, we seek to introduce these concepts to our readers. To do so, after general discussions like the review of literature and definitions, we have mentioned the different divisions of human perceptions, and then, we have discussed the features of constructional concepts and ways to recognize them. Finally, the outcomes and results of constructional concepts in different sciences are investigated.

Keywords: Constructional Concepts, Human Perceptions, Primary Concepts, Secondary Philosophical Concepts, Secondary Logical Concepts

\section{Introduction}

There Today, some new ideas that are generated from the principles of humanistic thought targeted the modern man and reced him from the path of God and drive him to mental deviation. Some of these thoughts are relative and sometimes cannot be acheived. Proponents of the idea are trying to find this theory, they deny the absolute fact. The souvenir of the theory for the man of the third millennium leads to confusion, emptiness and despair of materialism. Naturally, this astonishment threatens the abode of the hereafter for human. Meanwhile, realistic and compassionate thinkers always fight against these ideas and have tried to indicate the correct idea Therefore, Muslim scholars to isolate the true meaning of the concepts of credit have risen.

They first divide the science to real and credit science to say that the real science is constant and they know that the credit science includes the constant and dynamic credits to prove that something that is changeable is a part of credits .

For this reason, discussions with credit terms became popular among them. Credit to say philosophers to explain the concepts of the human mind and the minds of animals are known in generalized terms.

When they say "man is the animal that can speak, they mean to understand everything. Higher degree of generalization of human power or abstraction of conventions or secondary wisdoms. After defining the concepts of credit can be stated that there may be people with knowledge of their presence, to create a series of new conceptual and interact with the environment to be used.

The reasonable perception, which fulfills many human needs are called "credit concepts". Due to expansion of human power, is able to make general concepts and conventions because these concepts can be seconds or reasonable, necessary and ultimately comparable cases brought.

The analogy is that of inference. So, the conclusion of conventions, play a major role. The conventions of thought, philosophy and logical way of thinking achieved. In other words, conventions are the assumptions that the mind for meeting the needs of human life, and aspects of descriptive and assumptions and validity of its contract and has been linked with realities. Disintegration credit with a true understanding of perceptions, the result would be that the truth is achievable and what some of the relativity of things, pose, is not correct. Shahid Motahari said :

The purified perceptions separate the true understanding of the very necessary and separating them from each other very harmful and dangerous. This lack of separation that is killing many scientists.

Some conventions on comparable facts and rational methods for the truth, in the course of conventions and some to the contrary, the results of studies about the conventions on generalized facts and facts such as conventions relative 
concepts of variable and function are considered normal requirements (Motahari, vol. 6, p. 372). With regard to the above, the introduction of and recognize the conventions, it is necessary central issue of this paper is to understand the concepts of credit.

\section{Literature}

Discussion of the pale form has been around since ancient Islamic sciences. The root of this discussion can be found in science fiction, especially the senses, speech and innovative search. Because of the tendency of Muslims to this issue, trying to understand the meanings of the Qur'an. The work, which will help them to interpret the Quran (Ahmad Hashemi, p. 48). Understanding each subject to scientific understanding of language and words and terms of science. To seek knowledge, knows that every word in it is valid science, what is the intention of the word, by science for the Taliban remain secret.

That is why discussion of the science of jurisprudence, which is directly related to understanding the Word of God and the sayings of the Imams (peace be upon him), and he has become more so where, according Motahari, Perceptions, more to do There Principles (Motahari, vol. 13, pp. 717 and 730). The principles also open the question of whether laws are real or credit assignment and status.

Also, the inventor of the discussion of the religious and social orders. In this context, the role of the Islamic sciences have provoked Allameh Tabatabai attention to them formally conventions to the Islamic philosophy. He says:

Although efforts are appreciable predecessor scholars, but on conventions, a special word of them to us. So we had to take action in this regard were to draw up specific content (Tabatabai, Rasa'il ferocious, p. 123).

Motahari also believes that discussion of the works Alama their own initiative and without relying on the work of earlier philosophers raised (Motahari, vol. 13, 717). Some scholars said:

The credit is interpreted in the sense that the late Allameh have apparently not been in the works initiative. Nevertheless, he is not unheard of;

As Ibn Khaldun rational knowledge of science and science intersect and different circumstances and in a confluence between the ways these two types of knowledge is harmful (Davari Ardekani, 137).

\section{Definitions}

The word "credit" is usually the word "true" or "real" is used to refer to it, the things that we do not return. In philosophy, the word "credit" and "abstract" in a sense come. In general, what the outside world does not apply, the account name itself is abstract. In other words, conventions and abstract matters are referred to the existence and validity of vertical, such as universality, particularity and object. You may find out the origins of abstraction conventions and may not be made only by the human mind (Sajjad, 76 and 77)

Accordingly, philosophers, credit terms have several meanings and use for non-misleading and wrong, the difference between the meanings must be considered invalid. Including credit meanings are:

1. All categories of seconds, whether logical or philosophical, credit called and even incorporates the concepts of credit.

2. In other terms, credit to the concepts of law and morality, is allocated latter concepts called "norms" are called.

3. notions that have no external manifestation and do not mind using the imagination, are made. These concepts as "illusory" also called.

4. The validity of the other terms, the "authenticity" of being in the existence or nature is used. (Mesbah Yazdi, teaching philosophy, vol. 1, pp. 178 and 179).

5. credit limit and order of an object that is the object of giving. This action by seizing and imagination are done (Tabatabai, Rasa'il ferocious, p. 129)

It seems that the definition of the third and fifth are very close;

Reti are appropriate definitions for the concept of credit. Foreign and apply the concepts that are subjective and are made with the help of imagination. Thus, the active power of the human mind that is doing the practical validity. The judiciary, the characteristics of what he has received by emotional factors, to make something else. Active action branch to sequence the work object is valid. Principles and methods defined in the same Realism is thus the true understanding is that perceptions of credit.

True understanding, development and conceptual reality and self Alamrnd; but perceptions, assumptions that mind to meet the vital needs them and aspects of a situation and assumptions and are valid contract with the realities head and 
have nothing to do.

A true understanding of scientific or philosophical rational value and can be the result of them, but do not logical Perceptions value.

On the other hand, a true understanding of the natural needs of the organism and factors of his life not for the environment and the changing requirements of physical and environmental factors do not change; but Perceptions function of vital necessities and specific environmental factors and the changes they will change, and eventually true understanding, absolute and permanent and are necessary; whereas Perceptions are relative, temporary and unnecessary (see Motahari, vol. 6 , pp. 371 and 372).

\section{The Division of Human Perception}

Now it is appropriate, mention of the need to divide our perception; because this work will help us to understand better credit terms. Philosophers, reasonable human being has been divided into primary and secondary. Motahari this division has mentioned in his works and then says that this issue has been found only among the latter. Maybe it is exclusively Sabzevari. He believes that the only journeys that are included in one of the chapters of this discussion it is inhaled. (Motahari, vol. 5, p. 279) Attach the other believes that the relationship between the public and private secondary intelligible philosophical and conventions is absolute, ie secondary intelligible philosophical includes broad concepts like the concept of existence, of existence, the meaning of the concepts of non-existence, for nature is pure and additional concepts that some credit concept can also be incorporated into this category. (Fanai Eshkavari, p. 241) The second vote, whatever the concept is credible, reasonable secondary philosophical, but what of the secondary philosophical be read, perhaps the concept of credit and perhaps not. If we accept the idea that absolute conventions secondary intelligible and if we accept a second vote in which some philosophical categories seconds, conventions are, however, seeking to understand the classification categories defined secondary philosophical categories help understanding of conventions will greatly divided. Suggest that it is a reasonable secondary philosophical concepts inherent affinity credit, the late Allameh Tabatabai in his philosophical book has no definition of rational philosophical seconds. Only a short section of it reasonable that the cases cited to explain it is another matter. According to the above description is now divided into the categories described above. What we perceive it, or tangible, or sensible or imaginative as well. In other words, human perception is of three types: perception, perception, illusion and intellectual perception. Perception, perception directly by one of the external senses and inner senses done. If it is found as a result of this feeling in mind, "be sensible" is. Here's what the perception is immediate, the tangible image of the object in mind, otherwise reality stamped image on the outside, not in the mind. If communication and direct exposure of that object perceptible by the senses is cut, the same way that our mind, memory remain in the minds of the imagination or memory is stored and at this stage it is "imagination" and understanding that is called imaginary perception. Now, if some imagination of some tangible object that is common in other ways, we consider, our mind is common to all these people, a concept which could be all-inclusive. The overall concept of the infinite is true of many, including "reasonable" call. Categories are twofold:

Basic categories: straight facts are foreign concepts. Human reasoning faculty, all common forms that have been recorded by the imagination, to make common sense and wisdom in order to give them life. What level of intellect arises, in fact, the real object exists outside is the kind of objectivity and a sense of imagination and reasoning has gone three steps. These categories are the ones that we can refer to a sense or non-sense (intellectual) distinguish them from other things, such as humans. All essences are in our minds and qualify the answer is "moon" Indeed, they are of this category, namely that of the former. Therefore, any meaning, referring to sensory or intellectual object or objects, the object or objects carried on, for example, said: "This object is called the first reasonable .

Secondary categories: Concepts that direct foreign objects and areas are not the different things. These concepts are merely the objects they express judgment and therefore warrant its own special set of determinations in nature and in itself and specific creature is not available. These concepts, also not competent to answer "substantial" to come, such as lack of unity, necessity, diversity and opportunity. (Mesbah Yazdi, teaching philosophy, vol. 1, p. 178-176)

Secondary categories of two species.

Since these two species are due to occur when the predicate of the subject and the predicate is attributed topic, two over there as that is what we mean: First, where the container formwork presentations on the subject and the predicate its qualification both in mind, such as the general people. The species are called the secondary intelligible logic. Second, where the container presentations complainant (predicate) on the subject (Subject) qualification mind within subject (matter) to come (predicate) is out, as they say, "a single man" such as "reasonable philosophical seconds" (Motahari, vol. 5, pp. 279-277). 
The difference in primary and secondary categories

1. categories of statements that are proximate taken from foreign objects, ie, in the case of mediation and other Adrakyh not involved, but not secondary intelligible forms of objects, but are merely adjectives things, but not their attributes, available as a special case, but he attributes to be shipped, but can not say that this trait of his own, though he is not there.

2. The primary categories had a feeling and imagination, but reasonable seconds, had a feeling, imagination and not as apart; that is the first part of the sensory mind and not, for example, the necessity of a reasonable Thani, imagination and therefore does not make sense.

3. The primary categories are specific aspects, which means that to a certain type or a certain sex, or up to a specific category. But the general aspects are secondary intelligible and hence, the public affairs are considered.

4. The primary categories usually used in science. The primary rational philosophy can not be created. Out of the deal entirely intelligible;

But intelligible s logic associated with logic, ie, dealing entirely with the mind. Secondary rational philosophical have the same meanings public, constitute philosophy that deal with the mind and the outside. (Motahari, vol. 5, pp. 177171)

\section{Characteristics of Conventions}

The next issue to learn more about credit terms, the characteristics of these concepts. To address the characteristics of conventions, as an introduction to say:

Every living thing in the world is imperfections of life which is prerequisite may have available. Throughout his life, to overcome its deficiencies and this requirement seeks perfection and knows his own happiness. Creator To address this need, wit and sense of possession is established. In this way the human mind and sense of self-interest, and benefited from the wisdom, the knowledge gained and with knowledge needs to raise and sometimes takes help from his mettle.

Unlike animals interact with their environment, natural wisdom and benefit of his wisdom.In fact, the power of the human intellect is to earn a superior position in the universe, it turns out that only his special initiatives.

Conventions, which arose from the power of human intelligence to meet the demand, the most important of these initiatives are considered. In other words, human needs and responding to her inner feelings, to validate resorts. So we can say that conventions born human individual and social needs to achieve perfection and being superior to that of his inner feelings will follow. (Tabatabai, seven letters, p. 128)

The importance of the concept of credit, were expressed in the form of two essentially biological (biology) is raised. The first attempt to life.

Al-Hayat scholars in their studies have concluded that the organism is in a constant attempt. The constant effort to attract the interest and avoid realizing losses.

After each attempt and activity of the organism's head, it's purpose: to gain benefit or to avoid losses. Therefore, the existing activities and above all, human survival is completed.

The third principle is to adapt to the environment. Living in diligence, will have to survive, adapt to the environment. Since every living environment can be different from other creatures, therefore, needs inside living things will be different. So, to survive in any environment, it requires built-in tools and equipment for the special needs of the environment, not solve it. (Motahari, Collected Works, vol. 6, p. 374)

The result of these two principles of the human being for survival and adaptation to the environment, to develop concepts that knocks him to achieve the goal. These concepts are conventions.

Perceptions function of vital necessities and factors for the environment. The realization of the human inner feelings come and he needs to bring to life. He writes:

(Tabatabai, philosophy of realism, p. 100)

As it is apparent, the origin of making conventions of active forces, the formative forces of man is to survive. For example, animals that lay eggs due to its natural active branch concepts credit for laying hens are never there for them is the concept of credit in connection with the birth. Thus, the active forces we create our inner feelings and encourage us to do new actions.

The process involved three things: action, material and human. He said in this regard: So you'll have for your 
perception to action and the matter and give to myself. A child in the first days of life get the things to his mouth. Then he eats the things that cannot be eaten. The appetite eat just felt in his brain and then the name will be replaced, meaning and disciple -wanted, wanted, wanted - and the smell test, clean eating, and sometimes also understands that the matter at hand There, do not eat. Of course, then the name of eating and eating and corrosive action and their material and this sentence in his heart. " This should not be eaten and before saying" I want this to be desirable. " With an expression that the concept of "need" the ratio between the active force and the effect he is. (Of necessity) and the ratio of real and true though, but her man between the active force and effect do not directly affect his foreign, but always felt that going to happen between themselves and the scientific data to the activities of the branch. (Tabatabai, philosophy of realism, $\mathrm{p}$. 101).

People like Allama say that people use the active forces to meet the human needs (such as food). Their active forces which create feelings within to do an activity (such as eating) good for him, desirable and even essential. Therefore, one has to, if his perception of the act, and also to give the matter. In this process, as hunger is a real significance, but as the course of a sense of credibility. Person, who feels hunger, through its active forces, began building his reputation.

Then, as the process of becoming accredited makes and among them everything he had in order to help garlic, credibility, such as in the wake of the food, swallowing, etc .

The description of the results achieved:

A. Man or any other living creature to operate due to its active forces, makes some of the concepts of credit.

B. Overall enforcement of conventions, is to preserve it, which was active forces,

C. This depends on a set of facts before their conventions such as hunger and a bunch of his facts such as the course of action.

D. The credit terms given to an inner feelings can be generated and then fix it needs, it may be lost. So, conventions variable.

\section{Identifying Ways of Conventions}

There are two ways we can recognize credits:

To understand these concepts and conventions need to be twofold:

Common conventions

Practical conventions

Practical conventions, born man is felt, and feel, with active forces.

Emotions of man are of two types: Common sense should be the nature and function of natural materials such as absolute and utter love and private feelings and change transfer. As a result of these feelings, the two species can be distinguished conventions:

A. General conventions other variables constant, such as reliability and validity of the science community and devoted following;

B. Accompanying private conventions, such as the ugly and the beautiful, private and various forms of association; according to this introduction, we can now examine the components (roots and branches) in credit provisions in the conventions.

As frequently, the credit of disabled people in accordance with natural active forces and the development of human beings. Some human activity is not limited to society and to the individual concerned, such as nutrition. Some of the other activities of mankind, without social assumption was not realized, such as marriage. The conventions of the then divided into two branches: The social conventions; after society conventions. The main difference between the two branches of the conventions is that individual humans, the conventions are the first type, but are not acquired to society, then society will not emerge conventions. Each of these conventions is the principle that some of them are mentioned separately.

Conventions to community

Necessity: The first Perceptions of practical conventions, is of necessity.

The current issue of man, with a belief in the necessity.

This obligation equally "must" that every living creature that puts between himself and his actions.

Good and evil (good or bad):

The second credit is born out of necessity reputation, good and evil in the sense of warmth and lack of amenity is the cognitive. This credit is in the individual.

Choose lighter and easier: 
Humans naturally, to make their own affairs, without pain and is easy to follow actions. It comes from the painstaking work may face obstacles, and as a result it is not human needs. So always easy for him, the most prestigious.

The Employment and Social humans to achieve their purposes, of everything around him, uses and applies them.

He exploit this to achieve the objective, considered necessary.

Therefore, the principle of employment, the exploitation of others to achieve their goals, the conventions to the community is considered. Maybe this credit, at first glance, a kind of authenticity to the cruelty and self-interest, but He explains that the purpose of this credit is that human nature orientation and continuous development of all, your profit is will (employment credit) and for the benefit of all who will benefit (Social Credit) and seeks to benefit all social justice.

Credit Hasan justice and injustice evil), then shall employ credit ratings and credit community $\mathrm{H}$. justice and injustice is evil.

Compliance of man in the face of foreign objects and when will they be raided his active force, the perception has four modes: science, suspicion, doubt and delusion. Are any of these cases the works that man can expect from an action, satisfy? Of course, not. When the man of action, the work seeks, should know that the practice, involved in this work; because this knowledge is crucial in his decision to act. Just as human knowledge in its decision, that the determinant. In other cases (suspicion, doubt, delusion) have not created dogma. In this case, mutual understanding and have shaken and therefore can not be a trend. The origin of the principles of social fixed essences before. Five main stated are all principles and social conventions have before. (Tabatabai, Philosophy realism, p. 114-105) They are fixed essences of credit; credits that can be used to make other credit before taken into sociological principle. So, credit to these five principles are not only sociological.

\section{Conventions and Social Dimension}

Root of property: root of this principle dates back to the original allocation of credits before the community. In fact, the property is accounted for essentially completed. This has the effect of special permit any seized property. On the principle of credit derivatives. In terms of society, the allocation is useless and the first day society between the same and have different benefits, have the right to use property means property called and does the same - and resolve all possible possessions - has been credited.

Speech: The need to build word and status word is a key man and most animals vowels in the first phase of the community being aware of it. This necessity arises from the fact that every community large and small, need people to understand each other's intentions and menu of the talk and the like, for optimal performance.

President and subordinate: human social life, shows that the requirement of talent and instinct of employment and to create harmony and order, individuals as president, other people, and they employ the driver command. President of the society, such as the head of the body.

Some people order different from the other members of the body.

This role is also chairman of the rest of society. Based on this principle, conventions applied prohibit, punish, reward, etc. In equity mutual funds: Casual man credited meaning that the relationship is not the President and subordinate; but from the needs and the needs of individuals together, to come, such as different types of exchanges. For this type of conventions, "equality of parties" are said. In this manner there are orders; but these are the guidance not the orders of Molavi (Tabatabai, Philosophy realism, p. 133-1230).

\section{Conclusion}

Accordingly, the importance and status of science were obvious. As it is written in the introduction, Islamic scholars with the recognition of credit concepts of real meaning have tried deviation relativists think they are revealing the true meaning of human life to prove. There are many facts of science will sponsor our understanding of the sciences. Therefore, it can be argued that the concept of credit recognition in various sciences, has many positive impacts.

Motahari use credit concepts in science is divided into two categories:

A. In the social sciences: The laws of science when they are told, for example, a series of credit, or the credit is said to be owned, that these things have subjected a series of affairs. The human social life is not the choice of some contracts. These contracts are human situation into their own hands.

B. In philosophical terms: philosophers believe that it will develop two concepts of the human mind: The first concepts are directly outside. These concepts are derived from foreign examples and are come to mind. 
Second, there are concepts directly outside, but other concepts that are out there, they are abstractions. So, these concepts apply to foreign objects; but the concept does not apply to them, such as the concept of possibility. (Motahari, Collected Works, vol. 5, pp. 362 and 363) It can be found in this division that in all of the contracts, credit terms applied sciences such as literature, law, jurisprudence and principles. However, the science has a valuable place with rational arguments. The most important element in the sciences is how valid credit that their content to interested organizations.

Thus, the identification of conventions on human knowledge enables the conception of the knowledge.

\section{References}

Ibn Sina H., 1375 AD. Healing (Logic), Cairo, Al-Matbaeh Al-Amiri.

Davari Ardekani, Reza, 1984. The second Commemoration of Allameh Tabatabai, Tehran, Islamic Society of Cultural Research and Studies Institute of Philosophy.

Sajadi S J, 1962. Culture of rational sciences, Tehran, Ibn Sina Library.

Tabatabai, S. M. H., 1983. Sabe Essay, Qom, Matbah Al-Hekmah.

$1404 \mathrm{AH}$. We eventually Wisdom, Qom, Islamic publishing firm.

studies.

Bita, the principles of the philosophy of realism, by the effort of Khosroshahi, Seyed Hadi, Qom, the center of Islamic

Fanaei Eshkavari M., 1996. the second wise, first edition, Qom, Imam Khomeini Educational and Research Institute.

Mesbah-Yazdi M. T., 1987. Teaching Philosophy, Second Edition, Tehran, Islamic Propagation Organization.

Motahari M., 1992. Collected Works, First Edition, Tehran, Sadra printing.

Hashemi S. A, B and, Javaheralblageh, twelfth edition, Beirut, Dar al Alteras 